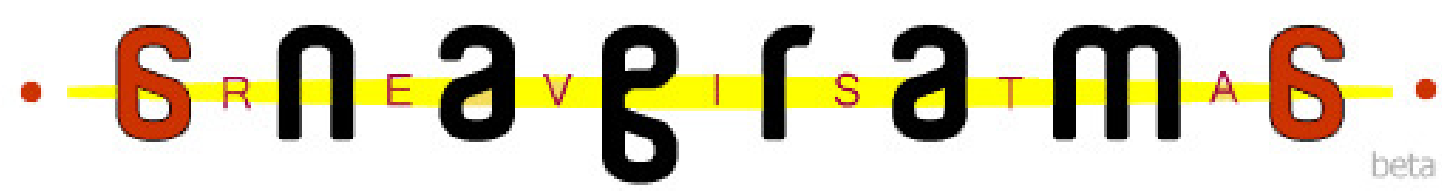

\section{no Rastro da História Indígena e da Língua Geral Amazônica}

\section{Raimunda Monata nunes da Silua ${ }^{1}$}

\section{RESUTO}

O artigo examina alguns aspectos constitutivos da estrutura da Historia Indígena da coesão interna, e suas estratégias de sobrevivência, também as transformações que foi passando a Língua Geral Amazônica (LGA), seguindo o seu Rastro Histórico desde a sua origem em meados do século XVI até seu declínio no século XIX, focando assim a perspectiva mais instrumental da LGA como instrumentação de meio de comunicação. Não deixamos, no entanto, de leva em conta o fundo e o contexto, isto é, a maneira como foi sua trajetória da ascensão ao declínio e sua situação atual.

Palauras-chaue: história indígena, língua geral amazônica, rastro

\begin{abstract}
Durante quase cinco séculos, os índios foram pensados como seres efêmeros, em transição para a cristandade, a civilização, a assimilação o desaparecimento. Hoje se sabe que as sociedades indígenas são a parte de nosso futuro e não só do nosso passado (Cunha, 1991: 22)
\end{abstract}

\section{Introdução}

A proposta de rastrear a História indígena e a Língua Geral, é optar por uma temática que pela profusão dos estudos, deveria estar esgotada. No entanto, o que se percebe é exatamente o contrário. Trata-se de um tema inesgotável, que desperta interesse, tanto de curiosos quanto de intelectuais e pesquisadores.

Esse é um universo que está longe de ser desvendado e, quanto mais se adentra, se descobre que há muito ainda para se descobrir. Suas características intrínsecas de hibridação, suas trajetórias históricas, as particularidades e especificidades que foram adquiridas e desenvolvidas em cada lugar do Brasil.

\footnotetext{
${ }^{1}$ Graduada e Licenciada em Ciências Sociais pela Universidade Federal da Amazonas (UFAM)
} 
A historia do Brasil "canônica" começa a partir do seu descobrimento, mas neste "paraíso" já havia habitantes, abre-se aqui uma discussão sobre a origem desses homens do Novo Mundo, de onde vieram. Eram primitivos? Seres animalizados? Qual a língua falada? Por todos estes questionamentos e junto à ganância e a ambição dos colonizadores ou invasores é que milhares de indígenas foram dominados, escravizados e principalmente dizimados.

A realidade amazônica dos povos indígenas com seus problemas e desafios foram e continuam sendo motivo de pesquisas e estudos. Dentro do atual contexto muitas barreiras pode-se dizer que os índios já conseguiram superar, mas nem sempre foi assim, houve momentos tenebrosos como os que ocorreram no período da Colonização e, as atrocidades sofridas nos séculos XVI, XVII, XVII e XIX.

\section{Trajetória, Estratépias e Dificuldades de Sobreuiuências nos Séculos KUl, KUII, KUIII E KIK}

$\mathrm{Na}$ época da colonização os povos indígenas, enfrentaram uma política deliberada de extermínio que conseguiu a redução da população indígena que era em torno de milhões em 1500 e hoje apenas alguns poucos 200 mil índios. Isto foi possível através das epidemias que alastraram - se sobre os índios, os aldeamentos, os interesses dos colonos da Coroa e da Igreja.

Povos e povos indígenas desapareceram da face da terra como conseqüência do que hoje se chama, num eufemismo envergonhado, o encontro de sociedades do Antigo e do Novo Mundo (CUNHA, 1991:12).

Pensando em "desinfetar" as "terras" da animalidade indígena, pois através de estudos levantados os índios do século XVI ficariam no meio termo entre o humano e o animal, isto é, a idéia de bestialidade era expressa pelos portugueses. Assim estes seres não poderiam vingar no Novo Mundo, pois era uma espécie degenerada que estava condenada a ser extinta, pois não haviam conseguido alcançar o estagio da "evolução"

Por isso, a partir do século XIX os índios que restaram foram categorizados em "bravos" e "domésticos ou mansos" o que continua remetendo a idéia de animalidade, um ser exótico que deve ser estudado, utilizado em guerras como mero objeto " buchas de canhão". 
Entretanto novos meios eram pensados como forma de "civilizar" e legitimar as ações de extinção dos índios. Os missionários deveriam "admoestar os índios", pois com isto os índios passariam a assimilação da nova nação e as suas terras, estes legítimos senhores da terra perderam todo o direito mesmo as terras das aldeias, ou seja, um processo de expropriação. Mas os passos de burlar os povos indígenas continuaram o trabalho escravo, a tutela orfanológica, os ofícios de índios que caracterizaram os "índios de caçadores" de outros índios e ate mesmo de forma genérica como índios povoadores. Após rastreamos a trajetória indígena, vamos conhecer através dos séculos como ocorreu as estratégias e as dificuldades de sobrevivência dos povos indígenas.

\subsection{Século KUI}

Através das crônicas quinhentistas, podemos observar que meados do século XVI a várzea amazônica possuir uma população numerosissima, que foi dizimada através das epidemias e dos apresamentos. Mas a historia indígena também se estende as terras firmes.

\section{2. Século KUII}

Neste século a várzea amazônica estava praticamente despovoada, as feitorias funcionavam como currais de mão-de-obra destinada a abastecer as fazendas do baixo Amazonas. Os descimentos de Índios da terra firme neste processo é que se constituiu o estrato neo-indigena da população ribeirinha.

\section{3. Século KUIIII}

Este foi à idade do ouro da economia missionária apoiada no trabalho indígena na exploração, na neutralização das especificidades culturais e lingüísticas das nações indígenas dissolvendo a diversidade das etnias. Logo que dividiu a Amazônia em lotes, distribuindo-os entre diferentes ordens religiosas. A Carta Régia de 1693 a 1694 concederam aos jesuítas a área de maior concentração indígena, que corresponde à margem esquerda, justamente entre os rios Negro e Iça.

Esta divisão provocou uma serie de conflitos, pois as outras ordens sentiram-se prejudicadas, em uma região onde "não é rico quem tem muitas terras, mas aquele que tem a maior quantidade de índios" (Beozzo, 1957: 45), com isto os jesuítas se tornaram os senhores dos índios e os senhores de tudo. 


\section{2. Ч. Século KIK}

O século heterogêneo, o único que conheceu três regimes políticos, agora não é, mas a mão-de-obra que persiste como principal fator, mas sim as Terras, não há política indígena, é também a época da extração da Borracha, onde os índios foram novamente escravizados.

\subsection{Os pouos indígenas do século KUl ao século KIK e a Língua Geral Amazônica.}

A geografia do médio e alto Amazonas abrigava diversas etnias dos Aparias aos Omaguá, estes relatos obtidos através dos documentos quinhentistas, seiscentista e setecentista apresentam como diversas tribos utilizaram de estratégias de sobrevivência, como fugir de uma terra para outra, como faziam os Tupinambás de acordo com Acunã. Estas estratégias era a tentativa de escapar dos "viveiros humanos" que eram resultados da ação predatória das expedições, também havia a questão do infanticídio como forma de manter o equilíbrio demográfico.

Durante os Séculos XVII e XVIII, centenas de rebeliões eclodiram em toda a Amazônia, as incontáveis resistências dos povos indígena: Tupinambá, Aruan, Nheengaiba, Pacajá, Caboquena, Guanavena, Manaó, Mayapena, Mura e tantos outros. Atos individuais de heroísmo existiram, como Ajuricaba. Para Caldas (1957: 48) ele é " símbolo do heroísmo amazonense, grande líder dos povos do rio Negro".

Mas aos poucos os índios foram perdendo a resistência, pois estavam debilitados e as dificuldades existentes forçavam a integração a ação missionária disto resultou uma incorporação dos indígenas como mão-de-obra servil das vilas e fazendas portuguesas e perda dos troncos lingüísticos que foram incorporados a Língua Geral Amazônica.

\section{A Língua Geral Amazônica}

A experiência histórica se transmite através de uma língua. Os povos indígenas que habitavam a Amazônia falavam centenas de línguas diferentes e durante milênios transmitiram o seu passado para as novas gerações através da tradição oral, uma vez que desconheciam a escritura. A Língua Geral Amazônica (LGA) atual de hoje (Nheengatu), segundo Rodrigues (2002) difere da língua Tupinambá e da língua geral do século XVIII. 
Embora a diferença em relação a esta ultima se devem não apenas a mudanças ocorridas com o passar do tempo (cerca de 250 anos), mas principalmente no vocabulário e os vários dialetos segundo as diferentes regiões em que ela veio a ser falada.

As línguas indígenas constituem um dos pontos para os quais os lingüistas brasileiros deverão voltar a sua atenção. Tem-se ai, sem duvida, a maior tarefa da lingüística no Brasil. (RODRIGUES, 1966, 1)

\subsection{A Origem}

A expressão "língua geral" surgiu a partir do século XVI, apesar de no Brasil ter tardado bastante o uso desta expressão. O padre Jose de Anchieta intitulou sua primeira gramática em 1595, “Arte de gramática da língua mais usada na costa do Brasil”, a mesma recebeu varias denominações de outros autores, mas o nome que se firmou ao longo do século XVII foi o de "Língua Brasílica" (isto é Tupinambá), a partir do século XIX passou a designar a mesma língua corrente na Província do Pará.

Contudo a língua Geral Amazônica desenvolveu-se inicialmente no Maranhão e no Pará, pois o litoral do Maranhão onde se estabeleceram os primeiros portugueses e suas tropas, as missões que foram penetrando nos núcleos de povoamento amazônico passaram a usa como veiculo de catequese nos séculos XVII e XVIII a língua geral amazônica.Porem havia duas línguas gerais, faladas em novos contextos sociais, a Língua Geral Paulista (Tupi) e Língua Geral Amazônica.

\subsection{A Eหpansão}

A LGA rompeu os limites das aldeias Tupinambás e expandisse por vilas, povoações e ganhou ate as cidades, ou seja, atingiu seu apogeu com uma universalidade regional. Cresceu com apoio institucional sob a proteção da administração colonial, estimulando seu uso nas escolas e a nas praticas religiosas. Assim a LGA criou seu próprio "Mapa" ate o século XIX onde começou o seu declínio com a perda progressiva para a língua Portuguesa, gerando um afastamento da LGA dos centros urbanos, das praticas sociais e foi perdendo seu prestigio ficando confinada as aldeias, como língua definitivamente indígena. 


\subsection{Declínio}

A situação demográfica relacionada com os falantes da LGA e os falantes da língua nacional o Português criaram uma dissonância com o resto do Brasil, apesar da LGA ser majoritária, mas proporcionalmente este quadro foi invertendo-se e o crescimento da Língua Portuguesa (LP) começa a ser notório, como demonstra alguns resultados de Censos e "Arrolamentos" que apesar de incompletos e imprecisos formam o arcabouço documental que apresentam a perda da supremacia da LGA, mesmo sem precisar uma cronologia dessa perda. Com o Diretório fruto da política mercantilista do Marques de Pombal, foi proibido o uso da língua materna de cada nação indígena ou da língua geral- o Nheengatu, e obriga o uso da língua portuguesa.

Portanto a partir daí surgiu o bilingüismo os falantes da LGA e da LP, nesse confronto a LGA vai perdendo para LP que agora é a "língua de prestigio", mas a LGA ainda possuir a função de "amansar" o índio "selvagem" e "brabo" enquanto a LP "civilizava" o " índio manso". Com isto é formado o quadro sociolingüístico local.

Entretanto no meio urbano o bilingüismo destaca-se em duas cidades Manaus e Belém, apesar de em Belém o monolinguismo ser mais presente com os falantes de português, era considerada como cidade mais "civilizada" e Manaus com os falantes da língua geral considerada uma cidade mais "tapuia".

Podemos observa que em Belém também predominava a Língua Vernácula (LV) e a LGA. Manaus igualmente a Belém predominava o bilingüismo ( LGA-LP), mas com o aumento do comercio através do Vapor que funcionou como veiculo de expansão do Português que acabou contribuindo para a portugalização da cidade e a entrada de Nordestino.

Conseqüentemente o processo de transição do bilingüismo (LGA-LP) para monolinguismo (LP) nas duas cidades amazônicas iniciaram em meados do século XIX, mesmo ainda sendo utilizada a LGA em alguns espaços como dentro do convívio familiar, por outro lado os espaços das escolas a LGA foi sendo retirada para abrir espaço para a língua de "status e prestigio", mesmo ocorrendo confrontos e conflitos de culturas " os poucos falantes de LGA que restaram nas duas cidades eram corpos sem alma" ( FREIRE, 2004: 209).

Com isto a LGA estava em estado agonizante, ficando circunscrita a região do alto Amazonas. Porém observando toda esta trajetória da LGA que passou por vários processos 
como guerras, revoltas como a Cabanagem que determinaram seu declínio e propiciaram a expansão da Língua Portuguesa.

\subsection{Situação Atual}

Apos vários momentos que atravessou a Língua Geral Amazônica, o novo quadro sociolingüístico da Amazônia retirou da LGA qualquer possibilidade de expansão novamente, tornando limitada a ser a língua apenas dos "tapuios" e "caboclos", ou seja, o Neengatu ao substituir as várias línguas indígenas, rompeu com a tradição oral e não constituiu um veículo escrito para transmitir as novas gerações as experiências passadas, apesar de ser dotada de um alfabeto. Silenciados os índios, os portugueses retomam a palavra e o primeiro ensaio sobre Amazônia é de autoria de Bernardo Berredo, um "capitão de cavalos" de nacionalidade lusa, que foi governador do Estado do Maranhão e Grão- Pará (1718-1722).

A partir de Berredo, até os dias de hoje, a historia da Amazônia se resume a uma parcialidade e primaria "visão dos vencedores". Outro escritor amazônico, o barão de Sant'Anna Nery resumiu o chamado processo civilizatório na Amazônia, com a seguinte frase "Nós trocamos o arco secular pela carabina", sem questionar aqui a carabina como agente de civilização, mas como um desfribador que deixa o homem amazônico entre dois mundos contraditórios, cortado de sua própria historia. Concordamos com Freire que afirma.

o fato de nos amazonenses, não sabemos mais manejar o arco secular de tradição oral e tão pouco aprendemos a usar a carabina de língua portuguesa para transmitir a experiência histórica vital. (FREIRE 1983: 37)

Mas o Rastro Histórico da LGA ainda a mantém latente mesmo confinada na passagem do século XX a ser apenas uma língua de índio. Na atualidade há uma política de retorno das línguas de cada etnia no processo escolar, ao lado do português, a declaração Universal dos Direitos Lingüísticos atribui a todas as línguas de comunidades lingüísticas, independente de classificações como oficial/ não- oficial; majoritária/ minoritária; escrita/ ágrafa etc.

A oficialização das línguas Nheengatu (LGA) nos rios Negro e Xié, do Baniwa no Rio Içana e afluentes e do Tukano no sistema Uaupés, essas três línguas são objetos da 
criação de uma jurisprudência para da centralidade a noção de sujeito monolíngüe. Conforme Almeida (2007:46) "contribuindo para superar as discriminações a que a população indígena está ainda sujeita", criando uma política de valorização das línguas indígenas.

\section{Considerações Finais}

Apontaremos considerações finais, não para oferecer respostas fechadas aos questionamentos, mas para suscitar novos questionamentos. Após rastreamos através da historia indígena do século XVI ao século XIX que corresponde ao questionamento sobre os maus tratos sofridos pelos indígenas nestes períodos que é fruto da ganância e ambição dos invasores de um preconceito racista que estigmatizou os habitantes como seres inferiores, legitimando a dizimação que se abateu sobre estes povos. Transformando as sociedades indígenas de hoje em fragmentos do que foram apenas resquícios de povos que resistiram e atravessaram momentos cruéis em sua Historia.

Contudo observamos também a trajetória e as tentativas de sobrevivência da Língua Geral Amazônica (LGA) através da literatura oral, atualmente podemos constatar um novo processo de inclusão como uma língua que permeou toda a sociedade e quase se tornou homogênea, mas que gradativamente foi sendo excluída.

Atualmente os estudos demonstram uma preocupação pela preservação e apropriação da memória histórica e como um momento para refletir a situação da Língua Geral Amazônica. Portanto diante deste cenário abrimos perspectivas para que o tema continue a ser pesquisado e reinterpretado, considerando sua importância.

\section{Referências Bibliográficas}

ALMEIDA, Alfredo Wagner B. (org.). Terras das Línguas: Lei Municipal de Oficialização de Línguas Indígenas. São Gabriel da Cachoeira Amazonas. Manaus PPGSCA/UFAM/Fund.Ford, 2007.

BEOZZO, José Oscar. Leis e Regimentos das Missões - Políticas Indigenista no Brasil. Ed. Loyola. SP, 1983.

CALDAS, Valério Garcia. Ajuricaba: símbolo do heroísmo amazonense. Sérgio Cardoso, Manaus. 1957. 
CUNHA, Manuela Carneiro da. A Historia dos Índios no Brasil, 2 edição, 5 reimpressão.1991

FREIRE, J.B. Rio Babel. A historia das línguas indígenas na Amazônia. Rio: Ed. UERJ, 2004.

"De fala boa ao português na Amazônia brasileira", publicado na revista Ameríndia, n B, 1983- pp 39 a 83- CNRS- Paris.

RODRIGUES, A.. Línguas brasileiras para o conhecimento das línguas indígenas. São Paulo: Loyola 1986.

"Tarefas da Lingüística no Brasil", publicado em Estudos Lingüísticos: Revista Brasileira de Lingüística Teórica e Aplicada, vol.1, n.1.1966. 